\title{
A Estátua Equestre de D. Pedro I e a Educação Matemática nas Escolas de Aprendizes Artífices no Início da República
}

\author{
The Equestrian Statue of D. Pedro I and Mathematics Education in Schools \\ of Apprentice Artificers in the Beginning of the Republic
}

Elmha Coelho Martins Moura*,**

\begin{abstract}
Resumo
Este artigo apresenta o uso de monumentos arquitetônicos como fonte de pesquisa em História da Educação Matemática das escolas de aprendizes artífices. A investigação foi realizada sob a perspectiva da História Cultural, com uso de documentos e literaturas referentes ao monumento Estátua Equestre de D. Pedro I, à Escola de Aprendizes e Artífices e ao Ensino de Matemática. Tendo como ponto de partida o monumento, foi realizada uma análise dos contextos histórico, político e social, no período de transição do Brasil Império para o início da República, inter-relacionado com a educação profissionalizante. Nessa conjuntura, pesquisou-se algumas circunstâncias da implantação das escolas de aprendizes artífices federais, e buscou-se estudar a Educação Matemática nessas escolas no período 1909-1926. Esse processo possibilitou discutir aspectos políticos, culturais, econômicos e suas dissensões, em um determinado tempo e território, para um ensino de matemática.
\end{abstract}

Palavras-chave: Ensino de Matemática. Ensino Profissionalizante. Monumento Arquitetônico.

\begin{abstract}
This paper presents the use of architectural monuments as a source of research in the History of Mathematics Education in schools of apprentice artificers. The research was conducted under the perspective of Cultural History, using documents and literature related to the Equestrian Statue of D. Pedro I monument, the School of Apprentice Artificers and Mathematics Teaching. Taking the monument as its starting point, an analysis of the historical-political and social context was held in the transition period between Brazil Empire and the beginning of the Republic related to professional education. In this juncture, weit was researched some circumstances of the schools implementation of federal apprentice artificers and learned about Mathematics Education in these schools during the period 1909-1926. This process made possible to discuss political, cultural, economic aspects and their differences in a particular time and territory for math education.
\end{abstract}

Keywords: Mathematics Teaching. Industrial Education. Architectural Monument.

\section{Introdução}

Os monumentos são vistos, comumente, como objetos urbanos que ajudam a compor o cenário da cidade, sejam eles os templos, as estátuas, os túmulos, as lápides, enfim, as obras

\footnotetext{
* Doutoranda em Educação Matemática pela Universidade Estadual Paulista "Júlio de Mesquita Filho" (UNESP), Rio Claro, São Paulo, Brasil. Endereço para correspondência: Av. 25, n.73, apto 33, Saúde, CEP: 13501-110, Rio Claro, São Paulo, Brasil. E-mail: elmhac@ yahoo.com.br

*** Autora financiada pelo Capes.

Bolema, Rio Claro (SP), v. 30, n. 56, p. 1244 - 1259, dez. 2016 
de arquitetura e de escultura construídas na intenção de rememorar algo. Porém, segundo alguns autores, o conceito de monumento vai mais além. Faria (1962) inclui as obras literárias e Le Goff (1992) considera que todo documento tem em si um caráter de monumento.

Entretanto, para que um objeto possa ser considerado como monumento é necessário que seja legitimado como tal por um regime jurídico, que avalia o mérito de sua conservação. O Instituto do Patrimônio Histórico e Artístico Nacional (IPHAN) é um desses órgãos encarregados de fiscalizar, proteger, identificar, restaurar, preservar e revitalizar os monumentos, sítios e bens móveis brasileiros.

As dimensões, o material utilizado, o estilo, os símbolos e o território dos monumentos são projetados de maneira a transmitir, de forma clara para quem os observa, uma determinada informação e/ou ideia. Esse procedimento é elaborado por grupos, por exemplo, o Estado e a Igreja, que, segundo Knauss (1999), intervêm no ambiente urbano com peças urbanas, às quais atribuem caráter histórico e artístico. O caráter histórico dos monumentos é relevante por permitir uma investigação desse rememorar organizado, em um tempo e espaço. A partir dessa intervenção, os cidadãos ressignificam os diversos territórios de seu cotidiano e constroem a sua identidade com a cidade.

Analisar as características físicas e a intencionalidade de um monumento requer averiguar o local ao qual ele foi destinado, apreender os símbolos e os aspectos físicos, investigar os documentos e/ou literaturas referentes ao seu processo de elaboração, construção e inauguração. Implica, também, em verificar a justificativa utilizada por seus idealizadores e responsáveis quando desenvolveram e erigiram aquele tipo de projeto, destinado a influenciar a memória coletiva da população de um determinado lugar.

Sendo assim, o objetivo deste artigo é mostrar o uso de monumentos arquitetônicos como fonte de pesquisa em História da Educação Matemática, para a análise de um contexto histórico: um ensino de matemática na rede federal do ensino profissionalizante no início da República Brasileira. Nesse sentido, a investigação tem como ponto de partida a Estátua Equestre de D. Pedro I, inaugurada em 30 de março de 1862, localizada na cidade do Rio de Janeiro, no Brasil.

A mudança do regime político de Monarquia para República repercutiu fortemente no ensino profissionalizante, no início do século XX. As transformações significativas ocorreram nas primeiras décadas de 1900, com a implantação um sistema educacional: as escolas de aprendizes artífices, organizada para formar trabalhadores em todo o território nacional, com um currículo preparado para tal finalidade. 
Nesse sentido, a pesquisa foi realizada sob a perspectiva da História Cultural que, para Burke (1999, p.267), “tem de conter em si mesma, várias línguas e pontos de vista, incluindo os dos vitoriosos e vencidos, homens e mulheres, os de dentro e os de fora, de contemporâneos e historiadores". Para Le Goff (1992), a história fermenta na memória coletiva. Essa memória situa-se: nos lugares monumentais como cemitérios, arquiteturas; nos lugares simbólicos como as comemorações; nos lugares físicos como os arquivos, as bibliotecas e os museus; nos lugares funcionais como os manuais, as autobiografias, entre outros.

Desses lugares físicos, foi no arquivo escolar da Escola de Aprendizes e Artífices do Estado de Mato Grosso (EAAMT), que documentos como Mapas e Boletins de Exames foram localizados e tais fontes, em conjunto com as literaturas sobre o ensino industrial, possibilitaram investigar a importância do ensino da Matemática nas escolas de aprendizes artífices, fundadas no início do século XX, nas capitais brasileiras.

Analisar o currículo das escolas de aprendizes artífices permitiu verificar quais disciplinas eram consideradas de maior importância para a formação do futuro jovem trabalhador; o decreto que regia esse ensino estabelecia a idade mínima de 10 anos e máxima de 16 anos para os alunos dessas escolas. Conforme documentos investigados nessa pesquisa, o ensino de matemática contribuiu, de forma significativa, para a formação desses artífices, considerados necessários para atender os interesses do início da República no Brasil.

Com o propósito de desenvolver um contexto histórico, político e social, e realizar uma discussão de alguns aspectos do Brasil Império e do Brasil República inter-relacionados com o ensino profissionalizante e o ensino de matemática para artífices, o texto que se segue aborda três tópicos. O primeiro apresenta as características e finalidades da estátua Equestre de D. Pedro I, bem como os conflitos ocorridos entre a monarquia e a república no local do monumento. No segundo, tendo como ponto de partida a Carta Magna de 1824, são discutidos aspectos legislativos referentes ao ensino profissionalizante. O terceiro traz uma análise do ensino da matemática nas escolas de aprendizes artífices. Finalmente, nas considerações finais apresenta-se um panorama e a análise das implicações desses três tópicos, sobre o ensino da matemática nas escolas profissionalizantes federais.

\section{Estátua Equestre de D. Pedro I: um conflito entre a Monarquia e a República no Brasil}

O primeiro modelo, um protótipo da Estátua Equestre de D. Pedro I, datado do ano de 1857 e assinado por Louis Rochet (1813-1878), é uma miniatura em bronze fundido, exposta 
no Museu Nacional de Belas Artes, na cidade do Rio de Janeiro. O protótipo impressiona pelo negro do bronze, pela preocupação com os detalhes da escultura e pela altivez do cavalo e do Imperador, este em trajes militares e em seus punhos erguidos sobre a cabeça, um papel com os dizeres: Independência ao Brazil (Figura 1).

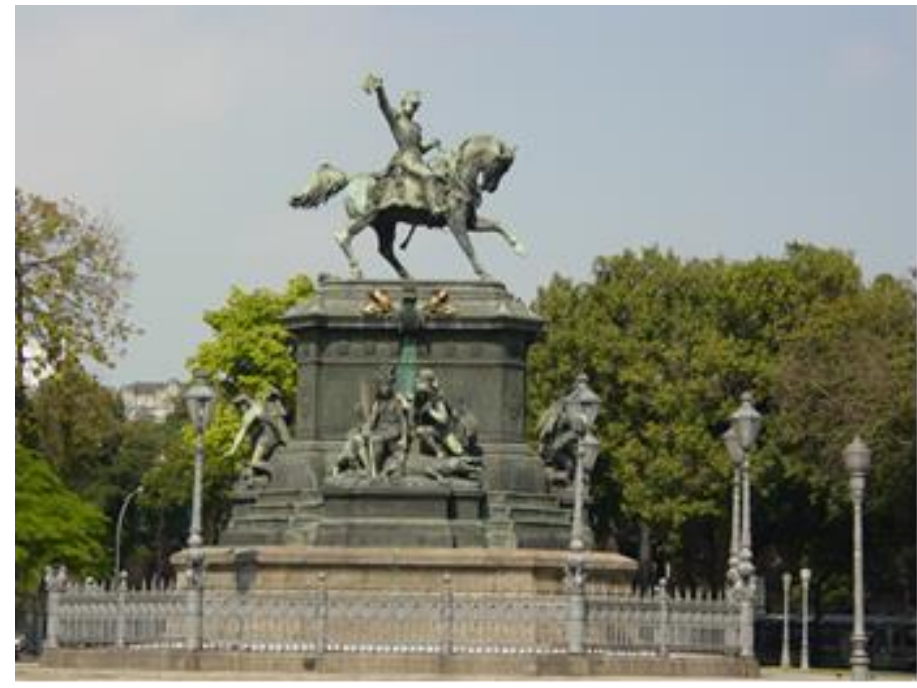

Figura 1 - Estátua Equestre de D. Pedro I, Rio de Janeiro/RJ

Fonte: http://www.patrimoniofluminense.rj.gov.br/patrimonio-cultural/estatua-equestre-de-d-pedro-i-rio-dejaneiro

No local onde a estátua foi erigida, no antigo Largo do Rocio ou Praça da Constituição - a atual Praça Tiradentes - no centro da capital fluminense, o monumento Equestre de D. Pedro I impressiona pela grandiosidade e elementos que não constam nos primeiros estudos de Rochet, como a base da estátua - um contemplar à parte. Nas faces da imensa base que apoia a escultura do Imperador há estátuas: de índios de diversas etnias em suas indumentárias e apetrechos como lanças, arcos, flechas e remos; de animais e plantas típicos das diversas regiões brasileiras e simbologias dos rios Madeira, Amazonas, São Francisco e Pará.

Contemplar esse monumento desperta sensações e memórias. O Imperador brasileiro, em trajes militares, lembra a pintura de Pedro Américo (1843-1905), mais conhecida como $O$ grito do Ipiranga (1822), onde o imperador posa com uma espada erguida em punho. Contudo, segundo Ribeiro (1999), no monumento na praça Tiradentes, o príncipe regente D. Pedro I, empunha a Constituição de 1824. A estátua em sua cor escura, monocromática, não expõe as cores dos objetos, mas de alguma forma, ao olhar o cavalo, ele parece branco, talvez uma possível associação com a imagem de Napoleão Bonaparte em seu cavalo. 
O Imperador estava ligado a dois acontecimentos importantes da história brasileira: a Independência e a Constituição Política do Estado. Essa memória, erguida na capital do Império, tinha como intuito simbolizar os feitos heroicos e instigar os jovens a imitá-los.

A Estátua Equestre de D. Pedro I, de acordo com Ribeiro (1999), foi construída pela iniciativa de Haddock Lobo (1817-1869), que solicitou à Câmara uma sessão especial no dia 07 de setembro de 1854, um dia nacional para tratar de um assunto nacional, a dívida sagrada da nação brasileira com aquele que a tornou livre, o príncipe herói, de ações exemplares, a quem os brasileiros deveriam ser eternamente gratos - D. Pedro I.

Para promoverem a representação do príncipe herói, foi necessário recorrer à História. O Instituto Histórico e Geográfico Brasileiro (IHGB) considerava que aqueles que participaram, junto com D. Pedro, do 7 de Setembro de 1822, também deveriam ser representados. Porém, trinta e dois anos depois do ocorrido, esses personagens participativos foram considerados esquecidos.

A princípio, a Estátua Equestre deveria ser apresentada com todos os atributos imperiais de D. Pedro I: coroa, cetro e manto sobre o uniforme militar. Tudo com dignidade, firmeza e triunfo, sobre um cavalo com um andar expressivo de grandeza. Somente reis, imperadores e grandes heróis eram representados em estátuas equestres; comparava-se, assim, D. Pedro I com seus antepassados europeus (RIBEIRO, 1999).

Em 1855, na Academia de Belas Artes, foram julgados os trinta e cinco modelos e desenhos para a construção da estátua. O vencedor foi o brasileiro João Maximiano Mafra (1823-1908), o seu projeto foi posto em prática sob os cuidados do ocupante do terceiro lugar da premiação, Louis Rochet, de nacionalidade francesa. A estátua deveria ser construída conforme o desenho do vencedor.

A inauguração do monumento foi prevista para o dia 25 de março de 1862, data da primeira Constituição do Império do Brasil, instituída no ano de 1824. O espaço escolhido foi a Praça da Constituição, atual Praça Tiradentes, local onde D. Pedro I havia jurado a Constituição política do Império. Assim, o dia e o local foram marcados para promover a representação do homenageado. De acordo com Ribeiro (1999), o Imperador D. Pedro I não foi representado com as insígnias imperiais, mas em uniforme militar e com a Carta Magna do país em mãos, de forma a simbolizar a Independência e a Constituição, passando a imagem de um Príncipe que não expressava uma monarquia absoluta, mas, sim, um império com bases constitucionais.

Diversos brasileiros, de acordo com Ribeiro (1999), se deslocaram de várias cidades para assistir à inauguração da Estátua no dia previsto, mas o evento foi adiado por D. Pedro II, 
que usou como justificativa às chuvas torrenciais ocorridas no Rio de Janeiro. Carvalho (1990) menciona que havia indícios de manifestações contrárias à inauguração naquele local. Uma nova data foi programada para o dia 30 de março de 1862, porém, apesar da inauguração, a Praça da Constituição tornou-se local e ocasião de uma revolta entre adeptos da Monarquia e da República. Segundo Carvalho (1990), as festividades e o lugar foram propícios para a revolta, por ter sido o mesmo local onde, em 21 de abril de 1792, fora realizado o enforcamento de Tiradentes, herói republicano. Foi um embate entre a memória de D. Pedro I, promovida pelo Governo, e a de Tiradentes, símbolo dos republicanos.

De acordo com Carvalho (1990, p. 55), a construção da origem do mito da República encontrou dificuldades em estabelecer um herói para o novo regime. "Heróis são símbolos poderosos, encarnações de ideias e aspirações, pontos de referências, fulcros de identificação coletiva”. São, por isso, instrumentos eficazes para influenciar os cidadãos em um processo de legitimação de regimes políticos.

Transformar os principais participantes do 15 de novembro em heróis, não foi tarefa fácil; o herói tem que ter a cara da nação, responder a alguma necessidade ou aspiração coletiva, refletir algum tipo de personalidade ou de comportamento que corresponda a um modelo coletivamente valorizado. Alguns prováveis heróis republicanos foram: Marechal Deodoro da Fonseca, Benjamim Constant e Floriano Peixoto. O êxito aconteceu onde menos se esperava - na imagem de Tiradentes (CARVALHO, 1990).

O tema da Inconfidência era capcioso para a elite culta do Segundo Reinado. O Imperador D. Pedro I era neto de Dona Maria I, rainha contra a qual os inconfidentes se rebelaram. Então, a exaltação aos inconfidentes e a Tiradentes, de alguma forma, acabava por ser uma oposição à Monarquia e a seus verdugos.

O primeiro conflito político em torno da figura de Tiradentes, de acordo com Carvalho (1990), ocorreu em 1862, por ocasião da inauguração da estátua de D. Pedro I. O liberal Teófilo Otoni, líder da revolta de 1842, chamou a estátua de mentira de bronze e a expressão virou palavra de ordem dos republicanos. Outro liberal, Pedro Luiz Pereira de Souza, compôs um poema para ser distribuído na inauguração da estátua; a polícia apreendeu os folhetos, mas o poema foi republicado em Ouro Preto, em 1888. Inúmeros foram os conflitos nesse local e a Praça da Constituição, ao longo dessas manifestações, passou a chamar-se Praça Tiradentes. Tais acontecimentos apontam para a efervescência social e política da época.

A ação de prestar reconhecimento aos personagens da História, como D. Pedro I e Tiradentes, conforme Knauss (1999) está quase sempre direcionada a personalidades que influíram no Estado e, por extensão, permite que a sociedade seja grata à sua ação. Dessa 
forma, a história da sociedade se confunde, tornando-se dependente da história do Estado; em suma, o enunciado da gratidão, para o autor, fixa simbolicamente a aliança entre o Estado e sociedade.

O monumento a D. Pedro I e a praça nomeada Tiradentes representam um território de conflitos políticos e sociais, ocasionados pela mudança do regime de uma Monarquia brasileira para uma República brasileira. Nessas dissensões pela manutenção dos símbolos dos personagens desses regimes, visando à formação e consolidação de um novo Brasil, havia também uma preocupação com a educação pública, responsável pela formação de um cidadão que atendesse aos ideais do novo regime republicano.

\section{Brasil República e as escolas de aprendizes artífices}

No período da fundação do Império no Brasil, segundo Fonseca (1961), episódio como a vitória dos liberais, imbuídos dos ideais da Revolução Francesa, sobre os conservadores, refletiu nos debates da Assembleia Constituinte de 1823, no tocante a uma nova orientação para o sistema educacional que se formava. Porém, nenhuma grande mudança ocorreu no ensino de ofício; mantinha-se a mentalidade que esse ramo de ensino deveria ser destinado somente aos humildes, aos pobres e aos desvalidos.

A Comissão da Assembleia Constituinte, encarregada de apresentar o projeto de Constituição para o Império do Brasil, entregou, no dia 30 de agosto de 1823, o trabalho que seria a Constituição de 1824 e, no artigo 254, constava que, com a emancipação lenta dos negros, haveria o cuidado de criar para eles estabelecimentos de educação religiosa e industrial. Havia no espírito dos legisladores a ideia que o ensino industrial devia ser destinado somente aos negros. Esse preceito, no entanto, não foi consagrado na Constituição que o Imperador D. Pedro I outorgou, em 25 de março de 1824 (FONSECA, 1961).

$\mathrm{Na}$ Constituição de 1824, não houve nenhum item que tratasse diretamente do ensino profissional, mas esse ensino foi favorecido quando o item XXV do artigo 179 foi redigido como: "Ficam abolidas as corporações de ofícios, seus juízes escrivães e mestres". Esse artigo libertou os aprendizes da tirania das Corporações de ofícios e dos Mestres; colocou um fim na obrigatoriedade da avaliação para o desempenho dos misteres profissionais realizada por essas associações, que acarretava uma série de desvantagens para os aprendizes. A extinção trouxe liberdade profissional (BRASIL, 1824).

No período de 1840 a 1865 , foram criadas casas de educandos artífices por dez governos provinciais, que adotaram a aprendizagem de ofícios no âmbito militar. O Asilo de 
Meninos Desvalidos, criado em 1875, na cidade do Rio de Janeiro, destacou-se dos demais estabelecimentos desse tipo de ensino. De acordo com Cunha (2000), os meninos eram levados ao Asilo pelas autoridades policiais; no local deveriam receber instrução primária e aprender os ofícios de tipografia, encadernação, alfaiataria, carpintaria, marcenaria, tornearia, entalhe, funilaria, ferraria, serralheria, courearia ou sapataria.

A abolição da escravatura (1888) e a Proclamação da República (1889), que pôs fím à Monarquia, ocasionaram a formação de um perfil diferenciado de trabalhador - estrangeiro e assalariado - e a de um novo cidadão brasileiro republicano. Com isso, era necessário realizar mudanças no sistema educacional, no âmbito do ensino profissional, que permaneceu, durante o início do século XX, direcionado especialmente para os mais pobres.

Foi em 1942, com a Lei Orgânica do Ensino Industrial, Decreto-Lei nº 4127, que esse tipo de educação deixou seu cunho assistencialista perante a legislação. Porém, foi somente na década de 1970, que o Governo Federal em conjunto com a mídia, comércio e indústria realizou uma campanha de valorização do ensino profissionalizante, como digno de ser frequentado pelos filhos da classe média brasileira.

A República foi proclamada por um golpe de Estado, de acordo com Cunha (2000), no desfecho de uma conspiração que reuniu liberais como Rui Barbosa, positivistas como coronel Benjamim Constant e monarquistas ressentidos, como o Marechal Deodoro da Fonseca. Nas primeiras décadas desse novo regime político, três processos sociais e econômicos combinaram-se para mudar a estrutura social, com repercussões nas questões educacionais, até mesmo na educação profissional: a imigração estrangeira, a urbanização e a industrialização.

O período histórico conhecido como Primeira República (1889-1930) teve, como primeiro presidente do Brasil, Marechal Deodoro da Fonseca (1827-1892), que decretou, no dia 03 de novembro de 1891, a dissolução do Congresso e o Estado de Sítio. Essa ação totalitária ocasionou o que ficou conhecida como a Primeira Revolta Armada, quando o Almirante Custódio (1840-1902), contando com a solidariedade de Floriano Peixoto (18391895) ameaçou, a bordo de seu navio, bombardear o Rio de Janeiro, caso o Presidente da República não renunciasse. Deodoro da Fonseca renunciou, no dia 23 de novembro de 1891, ao seu cargo de presidente, assumindo, em seu lugar, o vice-presidente Floriano Peixoto.

Segundo Fonseca (1961, p.161-162) "Por ocasião da proclamação da República existiam, em todo o País, 636 estabelecimentos industriais. Daquela data até 1909 fundaramse 3362 outros. Em vinte anos o crescimento havia sido extraordinário". O desenvolvimento da indústria indicava a urgência na implantação de estabelecimentos de ensino industrial, o 
crescimento não fora somente quantitativo; as necessidades das indústrias passaram a exigir trabalhadores com conhecimentos especializados. Cabia ao Governo tomar providências.

A 14 de junho de 1909, falecia Afonso Pena, então presidente do país, e, no mesmo dia, Nilo Peçanha (1867-1924) assumia seu lugar, trazendo o espírito preparado para a solução do problema da formação do trabalhador nacional para o desenvolvimento industrial emergente. De acordo com Fonseca (1961), três meses depois de Nilo Peçanha assumir a presidência, ele assinou o Decreto 7566, de 23 de setembro de 1909, criando, nas capitais dos Estados brasileiros, escolas de aprendizes artífices. Esse decreto representou o marco inicial das atividades do governo federal no campo do ensino de ofícios.

As escolas de aprendizes artífices surgiram com o caráter disciplinador social e de desenvolvimento industrial, caminho que, de acordo com a elite dominante da época, ajudaria a conduzir e a consolidar um Brasil republicano. Essas escolas eram destinadas ao ensino primário e gratuito e tinham teor assistencialista, por visarem habilitar como trabalhadores qualificados os filhos dos desprovidos da fortuna.

Os filhos dos desfavorecidos da fortuna, mencionados no Decreto $\mathrm{n}^{\circ} 7566$, eram, segundo Cunha (2000), os filhos de negros, ex-escravos, mendigos, rebeldes, prostitutas, desempregados, viciados, as crianças órfãs e outros em condições semelhantes. Essas crianças eram consideradas inerentes aos vícios, malandragens e às más tendências, e deveriam ser corrigidas com o ensino profissional que conduziria ao trabalho produtivo. Sendo assim, esse ensino seria digno de qualificar para o trabalho apenas uma determinada parcela da população, a menos favorecida, de maneira a atender os interesses da República brasileira que se estava estabelecendo.

\section{0 ensino de matemática para um trabalhador do início do regime da República}

No início da primeira República, ainda não existia a disciplina escolar Matemática. Havia as disciplinas de Aritmética, Álgebra, Geometria e Trigonometria, ministradas separadamente. Em 1928, no Colégio Pedro II, no Rio de Janeiro, sob os cuidados de Euclides Roxo (1890-1950), foi realizada uma reforma curricular no ensino dessas disciplinas que unificou todas essas matemáticas em uma única disciplina escolar: a Matemática. O processo de mudança foi conturbado, tanto no âmbito interno do Colégio Pedro II, quanto fora dele. A proposta da nova disciplina foi implementada em todo o país com a Reforma Francisco Campos (1931). Com isso, neste texto, o termo ensino de matemática significa os ensinos de Aritmética, Álgebra, Geometria e Trigonometria. 
Antes de 1926, os programas de ensino das escolas de aprendizes artífices, de acordo com Fonseca (1961), variavam de escola para escola, faltava-lhes unidade, cada uma desenvolvia a aprendizagem conforme os critérios dos diretores e professores. Em 1920, o Ministro da Agricultura, Indústria e Comércio, Ildefonso Simões Lopes (1866-1943), nomeou a Comissão conhecida como Serviço de Remodelação do Ensino Profissional Técnico, para propor medidas que remodelassem as escolas profissionais federais e dessem um denominador comum ao ensino praticado nos diferentes Estados da União.

A Consolidação dos dispositivos concernentes às escolas de aprendizes artífices, de 13 de novembro de 1926, estabeleceu um currículo para aprendizagem nas oficinas e regulamentou os currículos para o curso primário e o curso de desenho, ambos obrigatórios. O primeiro curso destinava-se aos alunos que não possuíam certificados do exame final das escolas de que eram oriundos, e o segundo destinava-se a todos os alunos. O currículo passava a ter as seguintes disciplinas: Português, Aritmética, Geometria Prática, Lições de coisas, Desenho e trabalhos manuais, Caligrafia, Ginástica e Canto Coral, Geografia e História do Brasil, Instrução Moral e Cívica, Elementos de Álgebra, Noções de Trigonometria, rudimentos de Física e Química, Desenho Industrial e Tecnologia de cada ofício.

Sendo assim, de 1909 até o ano de 1926, os conteúdos ministrados nas escolas de aprendizes artífices eram selecionados conforme cada estabelecimento, então, discutir os possíveis conteúdos do ensino da matemática vigentes naquele período, consiste em escolher uma escola com a possibilidade de possuir os documentos dos primórdios dessa instituição. Infelizmente, esse tipo de documentação é escasso nas diversas escolas da rede federal de ensino, conhecidas, atualmente, como os Institutos Federais de Educação, Ciência e Tecnologia (IF). Em 1926, com a Consolidação, houve uma unificação desse ensino, porém esses documentos, assim como as legislações anteriores, mencionam somente os nomes das disciplinas com suas respectivas séries e aulas semanais.

De acordo com Cunha (2000), as escolas federais de aprendizes artífices poderiam ofertar as seguintes oficinas: marcenaria, carpintaria, ferraria, serralheria, fundição, funilaria, mecânica, sapataria, selaria, alfaiataria, encadernação, ourivesaria, eletricidade, tornearia, escultura, pintura decorativa, modelagem e metais.

O aprendizado das oficinas, conforme Moura (2012), tinha duração de quatro anos e, após o seu término, o aprendiz poderia cursar mais dois anos complementares. Os trabalhos oficinais e manuais não poderiam exceder a quatro horas diárias para alunos do $1^{\circ}$ e $2^{\circ}$ ano e seis horas para os de $3^{\circ}$ e $4^{\circ}$ ano. As aulas teóricas e práticas não poderiam ter duração inferior a 50 minutos. 
Nos quatro anos de ensino, as horas-aulas semanais eram distribuídas da seguinte forma:

- $1^{\circ}$ ano: Desenho e Trabalhos Manuais (15 horas), Leitura e escrita (8 horas), Caligrafia (2 horas), Contas (6 horas);

- $2^{\circ}$ ano: Desenho e Trabalhos Manuais (16 horas), Leitura e escrita (6 horas), Caligrafia (2 horas), Contas (4 horas), Elementos de Geometria (2 horas);

- $3^{\circ}$ ano: Aprendizagem nas oficinas (18 horas), Desenho ornamental e de escala (8 horas), Português (3 horas), Caligrafia (2 horas), Aritmética (3 horas), Geometria (3 horas);

- $4^{\mathrm{o}}$ ano: Aprendizagem nas oficinas (24 horas), Desenho ornamental e de escala (6 horas), Desenho industrial e tecnologia (6 horas), Português (3 horas), Aritmética (3 horas), Geometria (3 horas).

As disciplinas com maior número de aulas semanais eram aquelas relacionadas com as práticas e aprendizagem do ofício e a de formação do artífice: Desenho e Trabalhos Manuais e Aprendizagem nas oficinas.

As disciplinas de desenho também possuíam um número elevado de aulas semanais e tal importância se deve à contribuição que traziam aos trabalhos do ofício. É preciso considerar que, para desenhar em uma escola profissionalizante, mais que os primeiros traços livres, eram necessários conhecimentos de geometria e aritmética, aliados aos conhecimentos de técnicas e instrumentos de desenho.

As disciplinas referentes à aritmética e geometria possibilitavam um bom desempenho na disciplina de desenho, porém, durante os quatro anos de ensino, havia, ainda, as disciplinas de Leitura e escrita, Caligrafia e Português, que excediam em 2 horas semanais as disciplinas Contas, Elementos de Geometria, Aritmética e Geometria. Isso significa que, ao final do curso, o aprendiz deveria ser um artífice capaz de ler, escrever, contar, desenhar e fazer o seu objeto de ofício. Esse objeto variava de acordo com a profissão escolhida, por exemplo, o futuro marceneiro deveria saber fazer artefatos em madeiras, o alfaiate as vestimentas, o sapateiro os calçados em couros. Para tanto, todos deveriam saber desenhar o objeto de seu oficio com precisão e rapidez, somente depois disso executar a construção do mesmo, de maneira eficaz, para evitar o desperdício de tempo e de material.

O aprendiz que desejasse se especializar um pouco mais na profissão cursava os dois anos de ensino complementares, que constavam das seguintes disciplinas: 
- $1^{\mathrm{o}}$ ano complementar: Aprendizagem nas oficinas (24 horas), Desenho industrial e tecnologia (9 horas), Geometria aplicada e noções de álgebra e de trigonometria (4 horas), Física experimental e noções de química (4 horas), Escrituração de oficinas e correspondência (4 horas);

- $2^{\circ}$ ano complementar: Aprendizagem nas oficinas (27 horas), Desenho industrial e tecnologia (9 horas), Noções de mecânica (2 horas), Noções de física e química aplicada (3 horas), Álgebra e trigonometria elementar (2 horas), Correspondência e escrituração de oficinas (3 horas).

Nesses dois anos complementares, foi introduzido o ensino de Física e Química, que excedia em horas semanais o ensino de Matemática, que continuou tendo sua importância na formação do artífice. Foram inseridas, também, as disciplinas de Correspondência e de Escrituração de oficinas, ao que parece, com ênfase na demanda burocrática do ofício. Esses anos complementares contribuíam para que o artífice - capaz de ler, escrever, contar, desenhar e construir o seu objeto de ofício - ampliasse seus conhecimentos em contato com conteúdos antes não ministrados no campo da Física, Química, Matemáticas e Português.

A distribuição da carga horária semanal do ensino de aprendizes artífices, segundo Moura (2012), era feita de forma que o educando, desde os $1^{\circ}$ e $2^{\circ}$ anos, tivesse contato teórico com o ensino de ofícios nas aulas de Desenho e Trabalho Manuais. Nos $3^{\circ}$ e $4^{\circ}$ anos, o aprendiz tinha aulas práticas com o ensino de Aprendizagem nas oficinas, a fim de que essas atividades pudessem ter continuidade nos $1^{\circ}$ e $2^{\circ}$ anos complementares. O ensino de Desenho era relevante, fundamental para elaboração das atividades nas oficinas, e ministrado ao longo dos seis anos de formação, com várias denominações, cada qual destinada a uma aplicação e ofício.

De acordo com o Mapa Geral de Exames da Escola de Aprendizes Artífices no Estado de Mato-Grosso (1935, 1940, 1941), as avaliações nessas escolas ainda continuaram separadas para cada uma das matemáticas, apesar das disciplinas de Aritmética, Álgebra e Geometria terem sido unificadas com a Reforma Francisco Campos (1931), quando passaram a ser denominadas disciplina de Matemática. Até o ano de 1941, não havia ocorrido mudança desses critérios para o ensino dessa disciplina; somente no Mapa Geral de Exames de 1942, ano da promulgação da Lei Orgânica do Ensino Industrial, é que apareceram as avaliações unificadas referente à disciplina de Matemática.

\section{Considerações finais}


A Carta Magna empunhada pelo Imperador D. Pedro I, na estátua equestre, tinha por finalidade organizar e regulamentar o Brasil Império. Mas, no que se refere ao ensino profissionalizante, esse documento não trouxe nenhuma menção, embora tivesse contemplado os aprendizes com um grande benefício: a liberdade profissional, ao abolir as Corporações de ofícios e as tiranias dos Mestres.

Do período da primeira Constituição brasileira, em 1824, à inauguração do primeiro monumento construído em praça pública no Brasil, em 1862 - a Estátua Equestre de D. Pedro I - a economia agrícola do país utilizava-se de mão de obra escrava, situação que contribuiu para o estereótipo de que trabalhos manuais eram indignos, próprios dos escravos e dos desafortunados. Aos filhos desses era destinado o ensino profissionalizante.

O cenário legislativo que conduzia esse tipo de ensino mudou significativamente em 1909, no início do Brasil República, com o Decreto que instituía as escolas de aprendizes e artífices em todos os Estados brasileiros. Antes disso, houve diversas propostas e discussões que intencionavam melhorar o ensino profissionalizante e mudar sua finalidade, mas não foram aprovadas. Um exemplo disso foi o projeto de Manuel Araújo Pôrto Alegre (18061879), que propôs, em 1852, o rompimento com a tradição ao programar a criação de uma escola profissional aberta a todas as classes sociais.

As discussões a respeito de um novo regime de governo, um Brasil republicano, aconteciam no âmbito da elite cultural, pois na época grande parte da população brasileira era analfabeta e o acesso às informações e às literaturas era privilégio dessa elite. Os monumentos construídos em praças públicas se constituíram em instrumentos de acesso à formação da memória coletiva da sociedade local. A Estátua Equestre de D. Pedro I foi um desses monumentos. Construída como o objetivo de expressar a gratidão do povo brasileiro, projetada para rememorar e vangloriar os feitos do Imperador-herói, o grande representante da Monarquia brasileira de natureza constitucional e independente; tornou-se objeto de conflitos de ideais entre os ativistas monarquistas e os republicanos. O local da Estátua tornou-se espaço de diversas manifestações desse conteúdo político, que se prolongou por algumas décadas, mesmo após a Proclamação da República, em 1889.

Nessa efervescência política, de implantar e consolidar a República e seus símbolos, surgiram discussões sobre a formação de uma nação brasileira republicana, com diferentes perspectivas para o desenvolvimento econômico do país, com o fim da escravidão. Essas discussões acabaram por influenciar a postura do governo e sociedade, quanto ao ensino para formação do cidadão e trabalhador brasileiro e, em particular ao ensino profissionalizante, 
trazendo implicações para o ensino de matemática para um trabalhador no início do regime da República.

No ensino profissionalizante, uma análise do número de aulas semanais das disciplinas dessa rede escolar possibilitou concluir que o aprendiz, ao término de seu curso, além de ter desenvolvido competência e adquirido saberes sobre o seu ofício, deveria estar habilitado para ler, escrever com boa caligrafia, contar e desenhar. Para desenhar, necessitava-se de conhecimentos de geometria e de aritmética, juntamente com técnicas de desenho, daí a importância e presença das matemáticas. Com isso, foi possível perceber que essas capacidades eram consideradas necessárias ao futuro artífice, por contemplarem os conhecimentos práticos para a realização dos trabalhos manuais, motivo pelo qual as disciplinas relacionadas a esses conhecimentos possuíam maior número de aulas semanais.

O ensino de matemática continuou importante nos dois anos complementares. Estava presente nas matemáticas de Geometria, Álgebra e Trigonometria, mas não havia um destaque no número de aulas semanais, como aconteceu com o Desenho e a Aprendizagem na oficina. Nesse ensino complementar, ampliou-se o ensino de matemática com a álgebra e a trigonometria, abriram-se espaços para novos conhecimentos relativos à Física e à Química e aos aspectos burocráticos da profissão. O desenho e a prática de ofício continuaram fundamentais para a formação complementar do artífice. As disciplinas referentes à história, geografia, ao canto e à educação física não foram contempladas no currículo.

As matemáticas estiveram presentes nos seis anos de formação - quatro primários e dois complementares - das escolas de aprendizes e artífices, disciplinas com carga horária significativa para o desenvolvimento de habilidades e competências de seus estudantes. Então, o ensino de Matemática foi importante para a formação de artífices, profissão destinada a afastar as crianças das más tendências e formar trabalhadores qualificados para atenderem os interesses industriais, de um período conhecido como a Primeira República no Brasil.

A Estátua Equestre de D. Pedro I foi utilizada como fonte de pesquisa, para iniciar uma análise de um contexto político, social e cultural do ensino profissionalizante e a implantação das escolas de aprendizes artífices no Brasil. Daí relacionou-se com a investigação da relevância do ensino de matemática na formação do trabalhador, no período de transição do Brasil Monarquia para o Brasil República. Na análise do contexto utilizaramse também os aspectos legislativos, tendo a Constituição de 1824 como ponto de partida.

Os monumentos apresentam-se como mais uma fonte de pesquisa para a História da Educação Matemática. O seu uso como fonte, em uma pesquisa historiográfica, varia de acordo com a intenção do pesquisador: 
- O monumento pode ser utilizado como um ponto de partida para a discussão de um contexto de um Ensino de Matemática, como no caso deste artigo;

- Pode ser utilizado para a própria construção de um contexto para um Ensino de Matemática;

- Como também, utilizado para a construção de um Ensino da Matemática.

Nesse sentido, o monumento precisa ter características e elementos históricos necessários à finalidade da investigação. Lembrando que Faria (1962) e Le Goff (1992), ampliaram o conceito de monumento, permitindo que o acervo de escolhas seja mais vasto, incluindo estátuas, edifícios, edifícios escolares, objetos, obras literárias e documentais.

\section{Referências}

BRASIL. Constituição Política do império do Brazil (de 25 de março de 1824). Constituição Política do Império do Brasil, elaborada por um Conselho de Estado e outorgada pelo Imperador D. Pedro I. Disponível em: 〈http://www.planalto.gov.br/ccivil 03/constituicao/constituicao24.htm>. Acesso em: 15 jun. 2015.

BRASIL. Decreto-Lei no 7566 de 23 de setembro de 1909. Cria nas capitais dos Estados Escolas de Aprendizes Artífices, para o ensino profissional primário e gratuito. Disponível em: < http://portal. mec.gov.br/setec/arquivos/pdf3/decreto_7566_1909.pdf >. Acesso em: 15 jun. 2015.

BRASIL. Decreto-Lei no 4127 de 30 de janeiro de 1942. Estabelece as bases de organização da rede federal de estabelecimentos de ensino industrial. Disponível em: < http://www2.camara.leg.br/legin /fed/declei/1940-1949/decreto-lei-4073-30-janeiro-1942-414503-publicacaooriginal-1-pe.html>. Acesso em: 15 jun. 2015.

BURKE, P. Variedades de História Cultural. São Paulo-Rio de Janeiro: Civilização Brasiliense, 1999.

CARVALHO, J. M. de. Formação das almas: o imaginário da República no Brasil. São Paulo: Companhia das Letras, 1990.

CUNHA, L. A. O ensino de ofícios nos primórdios da industrialização. São Paulo: Unesp, 2000.

ESCOLA DE APRENDIZES ARTÍFICES DE MATO GROSSO. Mapa Geral de Exames. Cuiabá, 1935- 1942. Arquivo morto da Escola.

FARIA, E. Dicionário escolar latino-português. Ministério da Educação e Cultura, 1962.

FONSECA, C. S. História do ensino industrial no Brasil. Rio de Janeiro: Escola Técnica Nacional, 1961. v. 1.

KNAUSS, P. Cidade Vaidosa: imagens urbanas do Rio de Janeiro. Rio de Janeiro: Sette Letras, 1999.

LE GOFF, J. História e Memória. Tradução de B. Leitão et al. Campinas: Editora da Unicamp, 1992.

MOURA, E. C. M. O ensino de matemática na Escola Industrial de Cuiabá/MT no período de 1942 a 1968. 2012. 127f. Dissertação (Mestrado em Educação Matemática) - Universidade Estatual Paulista, Rio Claro, 2012. 
RIBEIRO, M. E. de B. Memória em Bronze: estátua equestre de D. Pedro I. In: KNAUSS, P. (Coord.). Cidade Vaidosa. Rio de Janeiro: Sette Letras, 1999. p.15-44.

Submetido em Junho de 2015. Aprovado em Outubro de 2015. 